\title{
Effects of Distributed Generation on Grid System: A Survey
}

\author{
Hongyu Zhang \\ Science \& Technogy and Information \& Communication Bench, State Grid \\ Liaoning Electric Power Supply Co. Ltd., Shenyang, China \\ Email: zhy_sgccln@163.com
}

\begin{abstract}
With high efficiency and environmental protection, distributed generation (DG) technology has attracted much attention since its invention. It can be formed by various ways, including: photovoltaic power, the wind, fuel cell and micro turbine, etc. In this paper, the definition of distributed generation and its development are introduced briefly. However, it should be concerned that, the distributed generation system may cause a certain impact on the existing power system after its connection to grid; and its potential effect on the quality and the reliability on the security of electric system are also discussed.
\end{abstract}

Keywords: distributed generation (DG), development status, power system, effect

\section{Introduction}

China is a nation with large energy production and consumption, its energy demand grows rapidly with the rapid development of economy. In the long run, we may suffer from some problems that need to be improved urgently. For example, pressure to increase supply, shortage of energy resources, and contradiction in environment protection, backward energy technology and rural energy problems. To achieve a diversification and sustainable development of energy, it is an important way by developing recycled energy to meet our energy needs.

In such a social background, the traditional power supply mode has showed some limitations in its "big units, high power, and high voltage ". Distributed power generation (DG) with its definition can be summarized as: directly arranged in a distribution network in power load or facilities nearby, economic, efficient, reliable generation can be considered as a new way. Power facilities in distributed generation system are called distributed power, including wind power, solar power, fuel cell, micro gas turbine. These power sources are often small (below 50MW) and close to the user, so that they can output power directly supply to the near power load or meet the need of power grid. Compared with the traditional centralized energy, distributed generation has some advantages like small investment, flexible power generation mode, low power loss, conducive to environmental protection, etc. It is more economic and effective to use DG than the centralized power supply to meet the peak of power load. It has gotten more and more researches when we concern about the planning of modern electric power system. Operating with large power grid and DG has been suggested by many academics at home and abroad. They regard that as a main way to reduce energy consumption, to improve the reliability and flexibility of power system, and that will also develop in China's electric power industry. It will bring a series of influence to the network and the voltage of transmission distribution network, to the power quality, to the system protection and to the dispatching operation etc. after the interconnection of DG grid. 


\section{An Overview of DG}

At present, the power system has developed into a single centralized power supply system with large units, high power, and high voltage. However, with the continuous expansion of the network scale our requirements on power quality, reliability of energy supply security are becoming higher and higher. The difficulty, high cost, serious environmental pollution problems caused by the operating of the large scale power system has become a big problem. At the same time, the global energy crisis and environmental crisis has made it becomes an urgent demand for the development and utilization of new energy. Then, distributed generation attracts our attention in the twenty-first Century. In order to make up for the lack of power, and improve the transmission of large-scale power system, distributed generation (DG), which can be directly installed near its users, has attracted more and more attention in recent years.

Now, operating with large power grid and DG has been suggested by many academics at home and abroad. They regard that as a main way to reduce energy consumption, to improve the reliability and flexibility of power system, it will develop in the electric power industry in the twenty-first Century.

\subsection{The Definition and Characteristics of DG}

Distributed energy system (Distributed Energy Resources, DER) is an important direction in the development of energy industry in the developed countries. The technology is mature and has been popularized and applied. Up to now, we have no unified definition of the distributed energy system and the main reference definition is according to American or European institutions. The three corresponding proprietary abbreviated terms in English in the distributed energy system are the following: DG, DP, and DER.

(1) DG: any system that can generate electricity outside the traditional public power grid. Its original motivation includes power systems like internal combustion engines, gas turbines, micro gas turbine, fuel cell, small hydro power generation system and the solar energy (wind energy, waste energy and biomass energy) etc..

(2) DP: contains all the technology in DG, is a system that can store electricity by transforming electrical energy via a battery, flywheel, regenerative fuel cell, superconducting magnetic storage devices, hydropower energy storage equipment etc.

(3) DER: covers a broader concept, can generate electricity or heat in situ of the users or near them. It contains all of the technology in DG and DP, and includes those systems that are connected with the public power grid. User can sold redundant electric energy to the Public Power Corporation through local connection.

We can see the relationship between DG, DP and DER from their definitions that is showed above, DP contains DG, DER contains DP, i.e., their concept tends to be generalized from narrow.

Today, we are suffering from serious environmental pollution and energy shortage. Distributed energy system is applied more and more widely, its research is also more and more wide. "DER Benefits Analysis studies: Final Report" has made profound comments on 31 research reports on distributed energy system, it summarizes the features and evaluation criteria summary of distributed energy system. These research reports are considered the best in the quantitative characteristics of distributed energy system. There are also a large number of research reports on the characteristics of distributed energy system in China; they can be summed up like the following:

(1) It can utilize energy by comprehensive cascade utilization, with high energy utilization rate, it can save energy effectively. The conventional centralized energy supply way is relative single, when the users need both the electric power and other forms of energy, such as heat, especially energy for cool and hot water, it is difficult to realize energy be utilized synthetically only by using the electric power to meet the above needs. 
Distributed energy system, with its small scale, flexibility and other characteristics, can meet the needs of users and at the same time, overcome the difficulty that cold, heat cannot be transported in long distance, achieve the comprehensive cascade utilization of energy through the organic integration of different cycle.

(2) It makes up for the deficiency of the stability in the security of large power system. Several major outages in recent years, especially the blackouts of Eastern California, caused the daily economic loss of $\$ 3$ billion, can fully reflect the vulnerability of modern power system with centralized power supply mode. Cooperating with large power grid, through a distributed energy system near the user, we can greatly improve the reliability of power supply; maintain the supply to important users in case of power grid collapse and accidental disaster.

(3) Its small devices, small occupation area, less initial investment and the ability to reduce the transmission loss and the investment in corresponding transmission and distribution system, make it can meet the needs of special occasions. Distributed energy system is set up nearby according to the need of users, so as to cooperate with users as far as possible. Compared with the centralized energy system, it can prevent the energy loss in long-range transport and the investment in corresponding transmission and distribution system, so it is also economic. It provides flexible, energy saving comprehensive service for the end users. It is recommended to develop distributed energy system for those users who are not suitable for the laying of grid or in the western remote areas.

(4) It is friendly to our environment and its fuel diversification, has opened up a new direction for the utilization of renewable energy. Distributed energy systems mainly use a clean fuel as energy, at the same time, can be both environment friendly and have a high efficiency. Comparing with fossil energy, renewable energy such as solar energy, geothermal energy, wind energy are decentralized, have a lower energy density. The current renewable energy utilization system is in a small scale with low energy efficiency, so it is difficult to use them as a means of centralized power supply. On the contrary, distributed energy system is suitable for associating with renewable energy because its mall scale.

\subsection{The Present Development Situation of DG}

Distributed energy system began from the twentieth Century 70's, but the technology has not been taken seriously since the centralized power supply technology was not fully mature, the energy demand grew rapidly at that time. With the development of economy, the quality requirements of the energy supply increases, and the demand for heat, electricity and cool becomes gradual universal, the application of distributed energy system has gradually attracted people's attention. Its investment is low, and it is applicable to a wide range, this technology has become the most flexible and effective supplement for the country's total energy supply system. Now, distributed energy technologies with promising development, have been applied widely in Europe and America, Southeast Asia and other places.

China is a developing country. There is a big gap between our country and the developed countries in the energy consumption. According to the trend of economic development at present, China is still facing with quite serious energy problem. In the process of the development of economy and urbanization in our country, the construction of residential and industrial park has been in the forefront of the development. Currently, the city's construction planning should pay much attention to the problem on how to realize the regional overall energy supply, distributed energy system has a broad development space for this. In addition, it is also an important issue to develop distributed energy system in the central business district. According to the energy situation in China, our energy resources are relative poor, also the regional economic development is imbalanced. For those remote, backward western areas that are far from the economic 
developed regions. It needs a long time and huge investment to form a certain scale, powerful centralized northwest power system. So it cannot meet the needs for the current rapid economic development in the west areas. The distributed energy system can take advantages of rich natural gas resources and a variety of renewable energy there, provide a powerful support for the economic development of those western areas in a short time with less investment cost. For those southeast coastal areas with developed economy, there have been demands for diversification of energy products like those western developed countries, because of the increasing in living level.

With the rapid development of economic construction, the scale of the centralized energy supply grid in our country bulges rapidly. It cannot be ignored about the safety concerns brought by this. We could only prompt inhibit this trend by adjusting the energy supply structure reasonably and combining the distributed energy system and centralized supply effectively, so that to build a safer and more stable power system. According to the process of the energy industry in the western developed countries, it can be found: that it changed from the distributed energy supply to the centralized energy supply, but then returned to the distributed energy supply. This is not only because of the improvement of the living standards, but also the defects in centralized energy system. There is no doubt that, with the development of our society, energy industry in China will also meet the similar problems. It will help lay a solid foundation for the development of Chinese energy industry to construct a reasonable energy system by combining the centralized energy supply with the distributed energy system, increase the quality and reliability of the power grid.

\section{Introduction of DG Technology}

\subsection{Photovoltaic Power Generations}

Solar energy, a huge renewable energy, can deliver energy that is equivalent of 21 billion barrels of oil and equivalent to global daily energy consumption to the earth every $40 \mathrm{~s}$, according to estimates. At present, solar energy, considered as the most promising energy in the future, has an unlimited potential for its outstanding advantages among several new energy technology.

The main ways to make use of solar energy can be: solar photovoltaic power generation, solar thermal energy, solar power, solar energy used in photochemistry, solar energy used by biological utilization and solar light utilization. The solar photovoltaic power generation, which is considered as the most promising new energy technology, has developed rapidly in recent years with its excellent characteristics. All the developed countries have invested much in the research and the development of solar photovoltaic power generation, try to promote the process of industrialization actively, and develop its application vigorously.

Solar photovoltaic power generation is one way to convert sunlight into electrical energy by solar cells, which is the smallest unit in photoelectric conversion and the core of solar power generation system. A solar battery component can be made by the series-parallel connection of solar cell units and their package, with its power ranges from a few watts to several hundred watts. These solar cells can not only be used separately as the smallest unit of power, but also be series-parallel connected to build a solar battery square, so as to meet the output need of load power. Compared with conventional energy, solar energy resource has some advantages like the following:

(1) Inexhaustible;

(2) Can be gotten in situ, needn't transport;

(3) Distributes widely, can be used dispersedly;

(4) No pollution to the environment, and no damage to the ecology;

(5) Can be recycled. 


\subsection{Wind Power Generation}

China is rich in wind energy resources, which has a good development prospect. According to preliminary statistical results of the latest wind energy resources survey by national energy administration organizations, with Chinese Meteorological Bureau and other units, the total wind energy resources can be about 4.35 billion $\mathrm{kW}$ from a 10 -metre height from the land with technology can develop 297 million $\mathrm{kW}$, the area that technology can develop is about $200000 \mathrm{~km}^{2}$ and the potential amount of technology can be developed is about 79 million $\mathrm{kW}$. In addition, wind energy resources can be about 750 million $\mathrm{kW}$ from an 10-metre height from the sea, the total reserves of wind energy resources that can be developed and use is more than 1 billion $\mathrm{kW}$ from a 10-metre height in China.

Wind power generation comprises two energy conversion processes, from wind energy to mechanical energy and from mechanical energy to electric energy. Rotor blades of wind turbines generate torque to drive the wind wheel to rotate in the airflow and input the torque to the transmission system through the hub. Generators convert mechanical energy from the drive system into electrical energy with electromagnetic induction principle.

\subsection{Fuel Cell}

Fuel cell power generation can convert the chemical energy of chemical reaction into electrical energy directly. It does not need the engine process, so it will not be limited by Kano cycle. With high energy conversion efficiency (40\%-60\%), it is also environmental friendly, as it won't discharge sulfur oxide and nitrogen oxide. Moreover, it can also decrease more than $40 \%$ of the carbon dioxide emission, compare with conventional power plants. Because of these outstanding advantages, many countries and big companies pay much attention to the research and the development of fuel cell technology, which is considered as the cleanest and most efficient power generation technology in the twenty-first Century.

Hydrogen, as a fuel cell, can be produced from coal, natural gas and oil, can also be produced from plants, biological emissions, solar, wind and water electrolysis process. China is rich in natural gas resources, so is gas layer and biological resources. It can be said that hydrogen energy is inexhaustible, can be used as an absolute guarantee fuel to the fuel cell power generation.

There are different types of fuel cells, according to the different classification methods; they can be divided into different categories. According to the different electrolytes that is used, they can be divided into alkaline fuel cell (AFC), with potassium hydroxide as the electrolyte; the phosphoric acid fuel cell (PAFC), with concentrated phosphoric acid as the electrolyte; proton exchange membrane fuel cell (PEMFC), with sulfonic proton total fluorine or fluorinated exchange membrane as the electrolyte; the molten carbonate fuel cell (MCFC), with molten lithium and potassium carbonate or lithium sodium carbonate as the electrolyte; the hermaphroditic oxide fuel cell (SOFC), with a solid oxide for oxygen ion conductor, such as yttria, zirconia as the electrolyte. According to the working temperature, they can be divided into two types with low temperature and high temperature, low temperature fuel cell $\mathrm{AFC}$ (operate at a temperature of $100^{\circ} \mathrm{C}$ ), $\mathrm{PAFC}$ (temperature at $200^{\circ} \mathrm{C}$ ), PEMFC (operate at a temperature lower than $100^{\circ} \mathrm{C}$ ); high temperature fuel cell $\mathrm{MCFC}$ (operate at a temperature of $650^{\circ} \mathrm{C}$ ), SOFC (temperature in $1000^{\circ} \mathrm{C}$ ), the high temperature fuel cell is also called fuel cell that can be combining developed for high quality exhaust. 


\subsection{Micro-sized Gas Turbine}

Micro gas turbine can be defined as a very small gas turbine whose power is below hundreds of kilowatts. It uses natural gas, methane, gasoline, diesel oil for its fuel. When it is full loaded, its efficiency can reach to $30 \%$, its efficiency can be improved to $75 \%$ with the implementation of cogeneration. The micro gas turbine has the advantages of small volume, light weight, high power generation efficiency, low pollution, easy operation and maintenance etc. It is different from the wind power and photovoltaic power generation system as its output power can be regulated. Generally, the power output is relevant with the quantity of fuel, the more fuel, the greater output power.

\section{Influence of Grid Connection of DG on the existing Power System}

At present, distributed power supply capacity are relative small, in the existing equipment level, distributed power will not affect the stability of the power system of large area. But with the development of distributed power supply, it may affect the properties of the whole power system if the number of this small unit reaches to a certain level. Distributed power network, mainly operates in the distribution network, its impact can be expressed as following.

\subsection{Impact of DG on power quality}

4.1.1. Influence on Voltage Fluctuation: In the traditional distribution network, active, reactive load change with time will cause the fluctuation in system voltage. Along the end of the line, the kind of fluctuation grows. If the load is concentrated near the end of the system, voltage fluctuation will be the biggest, which should be avoided. Distributed power supply may have influence on system voltage fluctuation by two ways after its connection to distribution network: First, the distributed power and the local load operate coordinated. The output of distributed power increases (or decreases) when the load increases (or decreases), then the fluctuation of voltage will be suppressed. Second, distributed power supply cannot operate coordinated with local load. To wind power as an example, it is difficult to coordinate with local load operation because its power output depends on its speed and great volatility, this will also increase the voltage fluctuation of the system. There is no doubt that distributed generation may have some impacts on the fluctuation of system voltage when it is used in system. As long as the distributed power is operating, its fluctuant power output will have deep or slight impacts on the power grid voltage. In some cases, the fluctuation of voltage has become the main factor that restricts the capacity of the installed distributed power. Therefore, it has practical significance to have a comprehensive research on the voltage fluctuation of distributed power.

4.1.2. Harmonic: First, a distributed power itself is harmonic. Second, power electronic equipment is used in distributed power. To wind power as an example, regardless of the type of wind turbine, harmonic generator itself can be negligible; the true source of harmonic currents is from those power electronic components in wind turbine. Especially, for wind turbine with variable speed and constant frequency, its converter is always at working, there is a linear relationship between the harmonic current size and the basic power output, it means that the harmonic current size is related to the size and speed of wind. In the normal condition, harmonic interference depends on the design structure of the filter device, filter units installed in the converter, and the short-circuit capacity of related grid. 


\subsection{Impacts of DG on Safety and Reliability of the System}

When DG is interconnected in distribution network, it can bring the positive influence, also may have a negative impact on the security and reliability of the system, it depends on specific circumstances. If the distributed power supply accesses into the system as a standby power, it can partly eliminate the power grid load and congestion, improve the power transmission margin of the power grid. By adjusting the layout of distributed power supply and voltage in a proper way, distributed power supply can support the voltage in system and improve the overall level of system voltage; if the distributed power can ride through low voltage, the system can still operate when a fault occurs, this may help to alleviate the voltage sag and improve the performance in regulating the system voltage. All of these are beneficial to improve the reliability level of the system. But distributed power operation, connects with the grid, may also reduce the safety and reliability of the system. If the distributed power supply cannot ride through low voltage, it usually requires the distributed power be removed from the grid when some faults occur in the system. When the connected line is concurrent, distributed power supply will increase the drop of voltage instead of supporting the voltage. If the distributed power did not trip off network timely, it may cause some malfunction protection and equipment damage because of its misalignment, the line cannot recover to operate in time and increase the outage time. When the system outage occurs, fuel supplied for distributed power supply may interrupt or the auxiliary power will be lost. At the same time, distributed power will be out of work, cannot improve the reliability of power supply. If distribution network cannot match well with the relay protection of distributed power supply, relay protection may protect the malfunction and reduce the safety and reliability of the system. In addition, the improper installation location, capacity and connection may reduce the safety and reliability of the distribution network.

\subsection{Impacts of DG on System Protection}

Distribution network often is radial with only one power supply and its lines flow only in one way. Considering that $80 \%$ of fault in the distribution network is instantaneous, the design to install a reverse over current relay in the substation, an automatic reclosing device in the main feeder, and fuse protectors to protect the distribution network. According to the principle of "disconnecting the fault branch and reclosing transient fault only", the automatic reclosing device can be coherent on with the fuse and each fuse can be coherent on with the fuse in the former level and/or the next level branch to protect the distribution network line. Installing distributed power supply in the distribution network may bring the following several problems for the relay protection because of some changes in the distribution network structure:

(1) The sensitivity of line protection will reduce or its scope of protection will become narrow with the interconnection of DG distribution lines. In some positions of a line, it is unavailable to start the quick break protection; form a quick break protection dead zone, so the fault in line cannot be removed timely. Installing the distributed power in the quick break protection dead zone, could only clear the fault by the backup over current protection with no change in the protection system, which increases the influence of fault on the grid. Setting the quick break protection at a setting, it may cause the maladjustment in the quick break, over-current protection and other control device; result the protection of malfunction.

(2) Distributed power may cause the protection of malfunction when there is a fault between the adjacent lines. The detected value of fault current near the line will be greater than the setting value due to the effect of distributed power line protection when a fault occurs near the generating line, thereby causing the protection of malfunction, and the distributed power supply may trip without circuit trouble.

(3) The impact of distributed power on reclosing. With the interconnection of the DG 
distribution lines, if the line trips with a fault, an islanding will be formed to maintain the power and keep the voltage at the rated values. But the distributed power supply may not jump off the line with the reclosing action, which will bring two kinds of potential threats. First, contemporaneous reclosing. Due to the loss of power grid, it is very difficult for the power island to maintain full synchronization with the grid. During the mains supply tripped out to reclosing, the phase angle difference between them may appear in $0-360$ degrees. Circuit may protect the malfunction under the current, and make the reclosing lost the ability to recover from transient faults rapidly. Second, the reignition of the arc fault point. With the loss of power grid, the fault point by the distributed power may still maintain the fault current. When the reclosing occurs, the power grid power supply may cause the fault current jumping, the reignition of fault arc, insulation breakdown, and the accident expand further.

\subsection{Impacts of DG on the Power Market}

All kinds of distributed power generation can compete fairly in a unified and open trading market because of the rise of the electric power industry and the deregulation of electricity market, thereby providing a variety of choices for users:

(1) Different vendors;

(2) Different periods for use electricity;

(3) Different quality of the power supply;

(4) Different measurement methods;

(5) Different structure to account the fee;

(6) Different methods of payment;

(7) Different side management plans for users;

(8) Generating or storing the power on one's own.

The open of distribution network, introducing the power retail market, the retail electricity market competition brings business opportunities for power supply enterprises who own power plants and users who have their own distributed power. Users who have distributed power may have three choices in the retail electricity market:

(1) Getting electricity from the power grid;

(2) Generating their own power and provide for themselves;

(3) Generating power on their own and sell the power to the grid.

According to the price information in the power competition market and demand information in the retail electricity market, users can make use of the distributed power of their own, provide heating and power supply service to themselves or nearby users, make it play a greater role and result in greater efficiency. The establishment of the retail electricity market would also establish a retail electricity mechanism, so that power generation companies in any form can be used as the power supplier to provide power products for retail electricity market and compete fairly in the retail market.

\subsection{Other Impacts}

In addition to the above mentioned impacts on the system, there are still some other problems need to be further studied when distributed power supply is connected to the power system. For example, due to the rise of distributed generation, we need to establish corresponding laws, regulations and industry standards, to build standards for establishing the interconnection of a universal DG and distribution network; at the same time, in order to realize mutual coordination over DG systems and DG with distribution network and the scheduling of distributed power, we need some dynamic measurement in communication, GPS, DSP and the power system, we also need to research on the application of online measuring technology in distributed power generation etc.. DG can have an adverse effect on the reliability of power system, such as some DG fuel will interrupt to the power supply or the DG auxiliary will get lost when large system outage occurs, then DG will 
also be stopped, cannot improve the reliability of power supply; if DG doesn't match well with relay protection of distribution network, this may cause a protection of malfunction, and reduce the reliability of the system; the inadequate installation location, capacity and connection mode will also reduce the reliability of distribution network etc.

\section{Conclusion}

Sustainable economic development requirements have forced power system change the past operation mode, encouraged the access to distributed power generation systems, to alleviate the situation of energy shortage. At present, the distributed power generation technology is still developing in China. It is only in laboratory studies and hasn't been applied in a larger scale, which are mainly affected by the immature of the technology. In the future, researches should focus on reducing the cost of distributed generation system and ensuring the stability of the power system.

\section{References}

[1] Y. W. Liang, Z. J. Hu, Y. P. Chen. A Survey of Distributed Generation and Its Application in Power System. Power System Technology, 27, 71 (2003)

[2] Y. T. Liu, X. W. Cai, S. M. He. World Survey of Decentralized Energy. World Alliance of Decentralized Energy, 3, 45 (2004)

[3] H. B. Puttgen, P. R. MacGregor, F. C. Lambert. Distributed Generation: Semantic Hype or the Dawn of A New Era. IEEE Power and Energy Magazine, 1, 22 (2003)

[4] F. Z. Peng, X. Y. Ling, R. An. Editonial Special Issue on Distributed Power Generation. IEEE Power and Energy Magazine, 19, 1157 (2004)

[5] B. Li, T. Q. Liu, X. Y. Li. Impact of Distributed Generation on Power System Voltage Stability. Power System Technology, 33, 84 (2009)

[6] C. H. Liang, X. Z. Duan. Distributed Generation and Its impact on Power System. Automation of Electric Power Systems, 25, 53 (2001)

[7] H. G. Zhang, L. Z. Zhang, S. Y. Chen. Studies on the Impacts of Large Scale Wind Power Integration on the Security and Stability of Power Systems. Proceedings of the CSEE, 27, 45 (2007)

[8] J. K. Niu, G. S. Chen. Effects of Small Embedded Generation on Power Quality. IEEE Colloquium on Issues in Power Quality, 6, 1 (1995)

[9] X. H. Hu. Technology of Distributed Generation and Its Impacts on Power System. Electro Technical Journal, 10, 1 (2004)

[10] N. Damir. Emerging Technologies in Support of Smart Grids. IEEE Power and Energy Society General Meeting-Conversion and Delivery of Electrical Energy in the 21st Century, 1, 1 (2008)

[11] S. Y. Chen, S. F. Song, L. X. Li. Survey on Smart Grid Technology. Power System Technology, 33, 1 (2009)

[12] H. Slootweg, P. R. MacGregor. Smart Grids-the Future or Fantasy. Smart Metering-Making It Happen, 1, 1 (2009)

[13] Y. X. Yu. Technical Composition of Smart Grid and Its Implementation Sequence. Southern Power System Technology, 3, 1 (2009)

[14] Y. X. Yu, W. P. Luan. Smart Grid. Power System and Clean Energy, 25, 7 (2009)

[15] Y. F. Lin, J. Zhong, F. L. Wu. Discussion on Smart Grid Supporting Technologies. Power System Technology, 33, 8 (2009)

[16] Z. Xu, M. Gordon, M. Lind. Towards A Danish Power System with 50\% Wind: Smart Grids Activities in Denmark. Power \& Energy Society General Meeting (2009)

[17] Z. H. Zheng, Q. Ai. Present Situation of Research on Microgrid and Its Application Prospects in China. Power System Technology, 32, 27 (2008)

[18] M. E. H. Golshan, S. A. Arefifar. Distributed Generation、Reactive Sources and Network Configuration Planning for Power and Energy Loss Reduction. IEE Proceedings on Generation、Transmission and Distribution, 153, 127 (2006)

[19] A. Cano, F. Jurado. Optimum Location of Biomass-fuelled Gas Turbines in An Electric Systems. IEEE Power Engineering Society General Meeting (2006)

[20] A. Kazemi, M. Sadeghi. Distributed Generation Allocation for Loss Reduction and Voltage Improvement. Power and Energy Engineering Conference, 2, 1 (2009)

[21] A. S. Safigianni, G. N. Koutroumpezis, G. S. Demetzos. Investigation of the Distributed Generation Penetration in A Medium Voltage Distribution Network. Power Tech, 2, 1 (2009)

[22] G. N. Koutroumpezis, A. S. Safigianni. Optimum Distributed Generation Penetration in A Distribution Network. Power Tech, 2, 1 (2009) 
[23] C. S. Wang, Z. X. Xiao, S. X. Wang. Synthetical Control and Analysis of Microgrid. Automation of Electric Power Systems, 32, 89 (2008)

[24] F. Katiraei, M. R. Iravani. Power Management Strategies for A Microgrid with Multiple Distributed Generation Units. IEEE Transactions on Power Systems, 21, 1821 (2006)

[25] S. Rahman, M. Pipattanasomporn, Y. Teklu. Intelligent Distributed Autonomous Power Systems. IEEE Power Engineering Society General Meeting (2007)

[26] M. Pipattanasomporn, H. Feroze, S. Rahman. Multi-agent Systems in A Distributed Smart Grid : Design and Implementation. Power Systems Conference and Exposition (2009)

[27] J. Zhang, Q. Ai, X. G. Wang. Application of Multi-agent System in A Microgrid. Automation of Electric Power Systems, 32, 80 (2008)

[28] D. S. Popovic, E. E. Boskov. Advanced Fault Management as A Part of Smart Grid Solution. Smart Grids for Distribution. IET-CIRED (2008)

[29] P. Lombardi, M. Powalko, K. Rudion. Optimal Operation of A Virtual Power Plant. Power \& Energy Society General Meeting (2009)

[30] B. Y. Xu, T. Y. Li, Y. R. Xue. Smart Distribution Grid and Distribution Automation. Automation of Electric Power Systems, 33, 38 (2009)

[31] J. G. Yao, S. Yan, S. C. Yang. Practice and Prospects of Intelligent Dispatch with Chinese Characteristics. Automation of Electric Power Systems, 33, 16 (2009)

[32] M. Wang, M. Ding. Distributed Generation and Its Benefits. Journal of Hefei University of Technology, 27,355 (2004)

[33] X. H. Hu. Problems on Distributed-generation Resources and Its Networking. Technology Electro technical Journal, 10, 1 (2004)

[34] D. W. Hu, R. Z. Wang. Definition of Distributed Energy Resources and Discussion on Its Relationship with CCHP. Refrigeration and Air Conditioning, 5, 1 (2005)

[35] F. Xue, H. F. Wang. Grand Plan of Electric Power Resource in UK. Automation of Electric Power Systems, 31, 1 (2007)

[36] Y. W. Liang, Z. J. Hu, Y. P. Chen. A Survey of Distributed Generation and Its Application in Power System. Power System Technology, 27, 71 (2003)

[37] Y. Wang, Z. Y. Xie, E. W. Nie. Distributed-generation and Topological Construction of Its Networking Inverter. Electric Power Education in China, 1, 205 (2006)

[38] C. H. Wu, P. Xiao, H. Wu. A novel Method for Three-phase Current-source Inverter. Transactions of China Electro-technical Society, 22, 78 (2007)

[39] B. Liu, S. C. Wang. Development and Test of A $10 \mathrm{~kW}$ Transformer less 3 Phases Grid-tied Photovoltaic Inverter. Trends of Construction in China: Photovoltaic Energy Resources, 4, 42 (2005)

[40] Z. Q. Wang, S. Z. Zhu, S. X. Zhou. Controller Design for Interface Based Distributed Generation. Automation of Electric Power Systems, 28, 61 (2004)

[41] G. B. Jiang, Y. Q. Pei, X. Yang. Parallel Operation of Sinusoid Wave Inverters without Control Interconnections. Proceedings of the CSEE, 23, 94 (2003)

[42] J. Li, Y. Kang, J. Chen. A Hybrid Fuzzy-repetitive Control Scheme for 400Hz CVCF Inverters. Proceedings of the CSEE, 25, 54 (2005)

[43] M. Xie, K. Cai, X. S. Sheng. Output Control and Parallel Operation Control of 400Hz Single-phase Voltage-source Inverter. Proceedings of the CSEE, 26, 78 (2006)

[44] D. X. Zhang, X. H. Xu, L. Yang. The Impact of Distributed Generators on Distribution Network Over-voltage. Automation of Electric Power Systems, 31, 50 (2007)

[45] H. Hu, S. Wu, X. Xia. Computing the Maximum Penetration Level of Multiple Distributed Generators in Distribution Network Taking into Account Voltage Regulation Constraints. Proceedings of the CSEE, 26, 13 (2006)

[46] N. Jiang, J. R. Gong, D. Q. Gan. Computing the Maximum Penetrating Level of Distributed Generators in Distribution Network by Taking into Account of Harmonic Constraints. Automation of Electric Power Systems, 31, 19 (2007)

[47] H. Y. Chen, J. F. Chen, X. P. Yang. Planning for Distributed Generation in Distribution Network with Short-circuit Current Constraints. Automation of Electric Power Systems, 30, 16 (2006)

[48] C. S. Wang, K. Chen, Y. H. Xie. Sitting and Sizing of Distributed Generation in Distribution Network Expansion Planning. Automation of Electric Power Systems, 30, 38 (2006)

[49] S. Y. Chen, H. Z. Dai, X. M. Bai. Reliability Model of Wind Power Plants and Its Application. Proceedings of the CSEE, 20, 26 (2000)

[50] Z. Y. Liu, S. T. Tan, X. J. Zeng. Distributed Generation and Its Impact on Power System Analysis. North China Electric Power, 10, 18 (2004)

[51] Z. Y. Liu, X. J. Zeng, S. T. Tan. A Novel Scheme of Stability Control for Distributed Generation Systems. International Conference on Power System Technology (2004)

[52] H. G. Zhang, L. Z. Zhang, S. Y. Chen. Influence of Large Scale Wind Farms on Power System Small Signal Stability and Damping Characteristic. Power System Technology, 31, 75 (2007)

[53] H. L. Guan, H. X. Zhao, Y. N. Chi. Requirement for LV RT Capability of Wind Turbine Generator in Power System. Power System Technology, 31, 78 (2007)

[54] X. G. Wei, G. F. Tang. Effect of VSC-HVDC Applied on Improving Wind Farm Voltage Stability. 
Power System Technology, 31, 27 (2007)

[55] Y. N. Chi, Y. H. Liu, S. W. Wang. Study on Impact of Wind Power Integration on Power System. Power System Technology, 31, 77 (2007)

[56] H. J. Yu, J. M. Pan. Study on New Islanding Detecting Method for Grid-connected Power System. Proceedings of the CSU-EPSA, 17, 55 (2005)

[57] X. G. Wei, G. F. Tang, X. Y. Wei. Islanding Detection Method for Photovoltaic Grid-connected Power System. Transactions of China Electro-technical Society, 22, 157 (2007)

[58] X. Yi, Y. P. Lu. Islanding Algorithm of Distribution Networks with Distributed Generators. Power System Technology, 30, 50 (2006)

[59] S. X. Wang, X. J. Li, Z. X. Xiao, M. L. Liu. Multiagent Approach for Services Restoration of Distribution System Containing Distributed Generations. Automation of Electric Power Systems, 31, 61 (2007)

[60] Z. G. Lu, Y. X. Dong. Service Restoration Strategy for the Distribution System with DGs. Automation of Electric Power Systems, 31, 89 (2007)

[61] C. Z. Hu, J. P. Lu, L. H. Hu. Analysis of the Impact of DG on the Protection of Distribution System. Journal of Chongqing University, 29, 36 (2006)

[62] Y. L. Zhou, R. F. Li, Y. Z. Su. A New Relay Protective Scheme for Distributed Generations Interconnecting with $10 \mathrm{kV}$ Switching Station. High Voltage Engineering, 32, 105 (2006)

[63] X. Z. Wang, X. Chen, L. Luo. Research on the Coordination of Distributed Generation and Distribution System Protection. Relay, 34, 15 (2006)

[64] S. Wu, T. H. Mei, J. R. Gong. Voltage Fluctuation and Flicker Caused by Distributed Generation. Energy and Engineering, 4, 54 (2006)

[65] J. Wang, X. Y. Li, X. Y. Qiu. Power System Research on Distributed Generation Penetration. Automation of Electric Power Systems, 29, 90 (2005)

[66] Z. J. Zhang, J. D. Wang, J. Ma. Key Technology of Distributed Generation. Shanxi Electric Power, 2, 57 (2007)

[67] S. Q. Zhang, X. Y. Wang. Exploration and Practice in Management of Fujian Medium and Small Hydropower Plants Connected with the Power Grid. Hydropower Automation and Dam Monitoring, 29, $25(\mathbf{2 0 0 5})$

[68] J. C. Xu. Generating Technology of Velocity-varying System Used in Small Hydropower Stations. Water Resources and Hydropower Engineering, 35, 67 (2004)

[69] D. J. Zhou. Operation, Problems and Countermeasures of Yangbajing Geothermal Power Station in Tibet. Electric Power Construction, 24, 1 (2003)

[70] J. G. Sun, Z. B. Feng. Development and Potential of Combined Cooling, Heating and Power System. Gas Turbine Technology, 19, 11 (2006)

[71] Y. W. Weng, S. 1. Weng, M. Su. Distributed Power System Based on Micro Gas Turbine. Electric Power, 36,1 (2003)

[72] J. C. Zheng. Current Status and Prospects of Power Technologies at the Frontier. Electric Power, 32, 9 (1999)

[73] H. Cheng, Z. Xu. Energy Storage for Use with Distribution Power Generation. High Voltage Apparatus, $39,53(\mathbf{2 0 0 3})$

\section{Author}

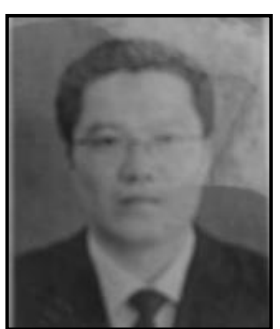

Hongyu Zhang, He comes from State Grid Liaoning Electric Power Supply Co. Ltd., Shenyang, China. His research interests include intelligent grid technology, distributed generation technology, etc. 
International Journal of Grid and Distributed Computing

Vol. 9, No. 8 (2016) 